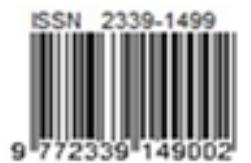

\title{
Perancangan Perbaikan Pelayanan Bongkar Muat Dermaga X Dengan Menggunakan Extend Simulasi
}

\author{
Misra Hartati ${ }^{1}$, Ahmad Kurniawan ${ }^{2}$, Melfa Yola ${ }^{3}$, Merry Siska ${ }^{4}$ \\ 1,2,3,4) Fakultas Sains dan Teknologi, Jurusan Teknik Industri, UIN Suska Riau \\ JI. HR. Soebrantas No. 155, Pekanbaru 28293 \\ Email:misrahartati@gmail.com, ahmadkurniawan765@gmail.com
}

\begin{abstract}
Large-scale logistics companies deliver products using sea transportation effectively. Company $X$ as one of the pioneer port containers service still has limitations both from minimal stacking capacity and limited equipment, 1 HMC unit and 1 unit reach adapter. The number of containers increases from 2014-2017, but the availability of tools and facilities that needed continue to cause overcapacity problem. This paper aims to determine the yard occupancy ratio (YOR), berth occupancy ratio (BOR) and utility equipment that are in accordance with the standards to prevent overcapacity at port $X$ until 2020. This study uses extend simulation method to make improvements and analysis of conditions that running, the results of the study are recommendations for the addition of 2 units of transport and the addition of reach units of 2 units. For the YOR value, additional capacity from 2,046 TEUs was made to 3,800 TEUs so that the initial maximum YOR was $139.8 \%$ to $75.3 \%$, while BOR still in maximum BOR capacity which is $24.0 \%$.
\end{abstract}

Keywords: Container, Descrette Event Simulation, ExtendSim, Port

\section{Abstrak}

Perusahaan pengiriman logistik skala besar menggunakan transportasi laut secara efektif. Pelabuhan $X$ sebagai pelabuhan perintis peti kemas masih memiliki keterbatasan baik dari kapasitas lapangan penumpukan yang minim dan keterbatasan alat, 1 unit HMC dan 1 unit reachsteker. Jumlah peti kemas yang terus meningkat dari tahun 2014-2017 namun ketersediaan alat dan sarana yang tetap menimbulkan kekhawatiran overcapacity. Penelitian ini bertujuan untuk mengetahui dan menetapkan nilai yard occupancy ratio (YOR), berth occupancy ratio (BOR) dan utilitas peralatan yang sesuai standar untuk mencegah overcapacity di pelabuhan $X$ hingga tahun 2020. Penelitian ini menggunakan simulasi extend untuk dilakukan perbaikan dan analisa terhadap kondisi yang berjalan, hasil dari penelitian adalah rekomendasi penambahan transport sebanyak 2 unit dan penambahan reachsteker sebanyak 2 unit. Untuk nilai YOR dilakukan penambahan kapasitas dari 2.046 TEU menjadi 3.800 TEU sehingga YOR maksimal awal 139,8\% menjadi 75,3\%, untuk nilai BOR tetap dikapasitas BOR maksimal 24,0\%.

Kata Kunci: Peti Kemas, Simulasi Diskrit, ExtendSim, Pelabuhan

\section{Pendahuluan}

Pengiriman logistik dengan skala besar lebih efektif menggunakan transportasi laut. Transportasi laut sebagai tulang punggung perdagangan dunia memerlukan fasilitas untuk bongkar-muat barang yang disebut pelabuhan. Pelabuhan $X$ sendiri merupakan salah satu pelabuhan dalam pelayanan CPO terbesar di Asia Tengara namun selain itu juga merupakan pelabuhan perintis peti kemas mulai tahun 2014.

Berdasarkan data pelayanan peti kemas di dermaga C Pelabuhan X (Gambar 1) terlihat terjadi peningkatan dari pertama kali beroperasi tahun 2014 sebesar 25.340 box, dan pada tahun 2017 jumlah peti kemas yang dilayani menjadi 85.349 box.

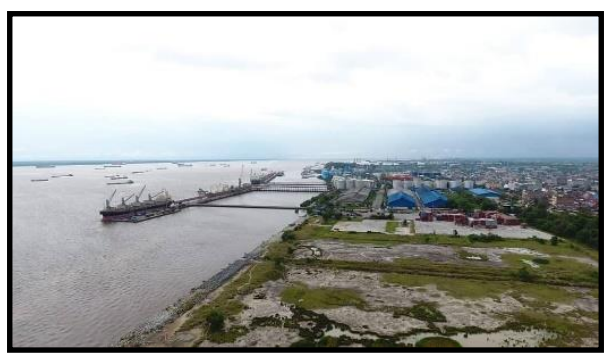

Gambar 1 Kondisi lapangan penumpukan 
Terjadi peningkatan yang sangat signifikan dari pertama kali beroperasi sampai pada tahun 2017 sedangkan kapasitas alat-alat yang digunakan untuk bongkar muat tetap sehingga terjadi waiting time untuk pelayanan peti kemas (Gambar 2).

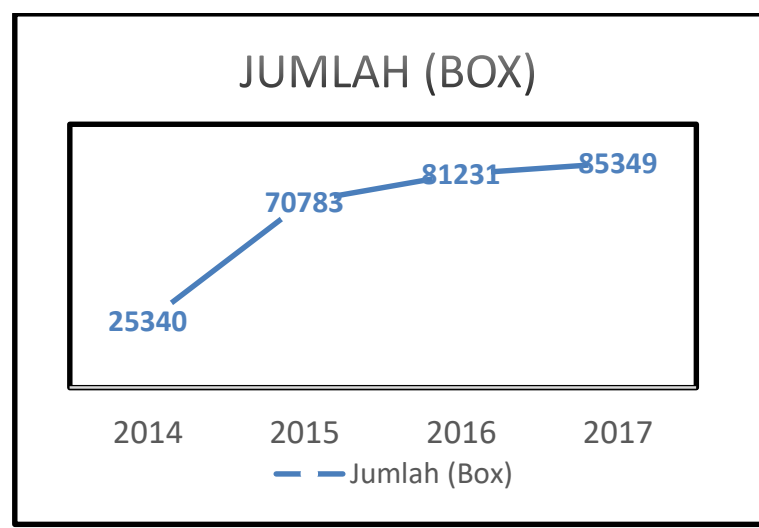

Gambar 2 Jumlah pelayanan peti kemas

Selain itu masalah yang dikhawatirkan akan terjadi pada dermaga $\mathrm{C}$ Pelabuhan $\mathrm{X}$ adalah overcapacity hal ini dapat terjadi apabila pelayanan di dermaga tetap namun jumlah peti kemas yang dilayani terus meningkat dari tahun ketahun sesuai data yang terlihat, overcapacity tersebut memberikan ancaman terjadinya kongesti dan stagnasi (Danu dan Tirto, 2017). Kongesti adalah kemacetan yang disebabkan oleh banyaknya peti kemas yang melebihi kapasitas, sedangkan stagnasi adalah keadaan terhenti yang menyebabkan kedatangan kapal terhambat (Fadillah, 2018).

Berdasarkan kondisi yang terdapat di dermaga $C$ Pelabuhan $X$ yang selalu mengalami peningkatan dari tahun ke tahun, kedatangan kapal yang bersifat dinamis dan tidak dapat diprediksi, maka tidak dapat dilakukan perhitungan perencanaan dermaga secara manual. Karena hasil yang didapat tidak akan akurat, sehingga diperlukan pendekatan simulasi (Banks, J., Carson, J. S., Nelson, B. L. dan Nicol, D. M., 2005) )untuk menyelesaikan masalah antrian pada dermaga $C$ Pelabuhan $X$ (Siswadi dan Mujiarto, 2013). Simulasi sistem dilakukan dengan menggunakan software Extendsim (ExtendSim,2017) dengan meramalkan dan memberikan skenario untuk beberapa tahun kedepan agar pelayanan peti kemas tidak terjadi masalah waktu tunggu pelayanan (Triatmodjo, 2010), (Sutini, 2017). Penelitian ini bertujuan untuk:

a. Memodelkan sistem nyata dan mensimulasikan (Rohmandani, 2009 )sistem bongkar-muat di Pelabuhan X.

b. Mengetahui dan menetapkan skenario nilai Yard Occupancy Ratio (YOR), Berth Occupancy Ratio (BOR) dan Utilitas Peralatan yang sesuai standar untuk mencegah overcapacity di Pelabuhan X hingga tahun 2020.

\section{Metode Penelitian}

Langkah-langkah penelitian ini adalah sebagai berikut:

\section{a. Membuat model konseptual dengan menggunakan ACD}

Untuk bisa menggambarkan bagaimana kondisi dilokasi penelitian kedalam program komputer maka diperlukan pembuatan model terlebih dahulu, model yang dihasilkan akan menggambarkan bagaimana kondisi bongkar muat dilokasi dengan sebenarnya. Merancang model dilakukan menggunakan ACD (Activity Cycle Diagram), pengolahan data ACD adalah untuk melihat berapa banyak entity dalam sistem (Kang dan Choi, 2010).

\section{b. Menentukan distribusi data}

Data digunakan sebagai dasar pembuatan model. pengolahan data pada simulasi menggunakan distribusi data tersebut.

c. Perancangan model extendsim

Setelah dilakukan perancangan model konseptual dengan menggunakan ACD selanjutnya dilakukan perancangan model Extendsim dilakukan untuk memindahkan model yang telah dirancang sebelumnya kedalam program Extendsim.

d. Penentuan jumlah replikasi

Menentukan jumlah replikasi dilakukan untuk menentukan berapa banyak replikasi optimal yang dibutuhkan dalam menjalankan simulasi.

\section{e. Verifikasi dan validasi}

Verifikasi model dilakukan untuk menentukan apakah model yang telah dibuat sudah menggambarkan kondisi nyata tatau belum, verifikasi digunakan untuk memastikan model sudah tepat dan dapat dinyatakan sesuai dengan sistem nyata. Validasi digunakan untuk memvalidkan data yang telah dikumpulkan sebelumnya, apabila data valid maka simulasi dapat dilanjutkan, namun apabila data tidak valid maka harus dilakukan pengambilan data ulang. Uji Validitas dilakukan dengan Uji Independensi.

\section{f. Menyusun skenario}

Setelah dilakukan validasi maka langkah selanjutnya adalah melakukan penyusunan skenario perbaikan yang akan dilakukan untuk meningkatkan pelayanan dermaga.

\section{g. Menjalankan simulasi}

Simulasi dijalankan dan akan dilihat jumlah peti kemas yang dilayani dan utilitasnya. Simulasi perbaikan dijalankan sebanyak jumlah skenario perbaikan yang dirancang sebelumnya. 
DOI: http://dx.doi.org/10.26593/jrsi.v7i2.2769.65-72

h. Compare dan Pemilihan Skenario

Setelah hasil nya didapat maka langkah selanjutnya adalah melakukan permbandingan hasil yaitu dengan melihat output dari peti kemas dan juga utilitas peralatan tertinggi.

i. Peramalan Peti kemas dan Kapal

Peramalan arus peti kemas dilakukan untuk mengetahui jumlah peti kemas dan kapal yang dilayani hingga tahun 2020, peramalan dilakukan sebagai landasan perhitungan nilai YOR dan BOR.

j. Perhitungan Nilai YOR dan BOR

Perhitungan niai YOR dan BOR dilakukan berdasarkan hasil peramalan, apabila melebihi standar yang telah ditetapkan maka akan dilakukan rekomendasi penambahan kapasitas agar tetap menampung peti kemas hingga desember 2020 .

k. Analisa Perbaikan Prosedur

Analisa perbaikan prosedur dilakukan sebagai langkah tambahan dari simulasi, perbaikan prosedur dilakukan berdasarkan hasil simulasi maupun hasil pengamatan kondisi lapangan.

\section{Hasil dan Pembahasan}

\section{a. Perancangan Model ACD}

Tahap ini adalah tahap pertama yaitu memodelkan sistem bongkar muat peti kemas dengan model konseptual dengan menggunakan activity cycle diagram (ACD).

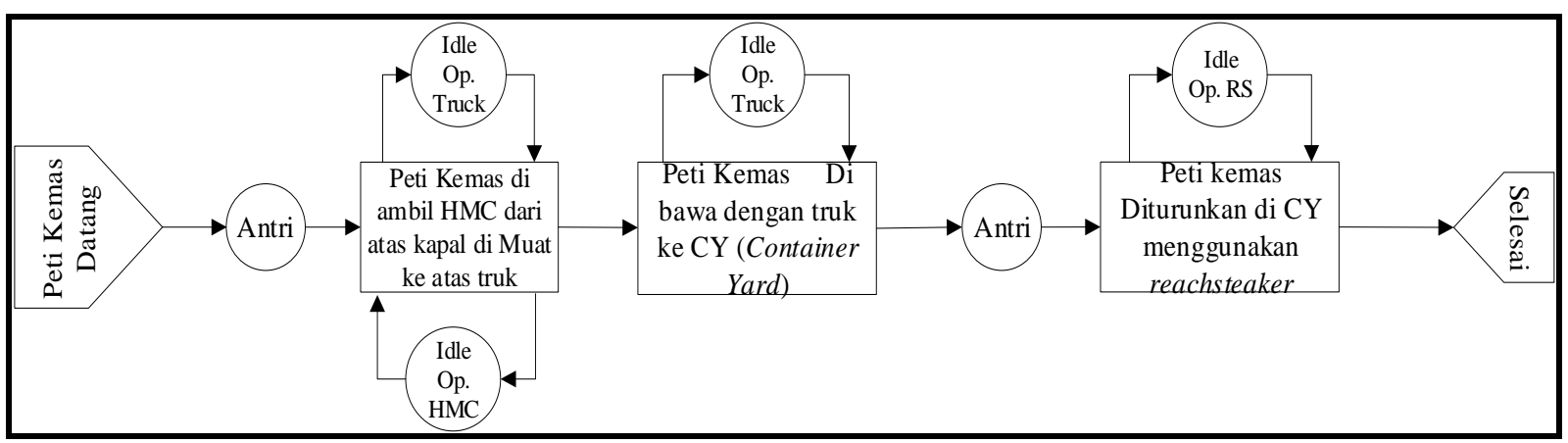

Gambar 3 ACD model 1

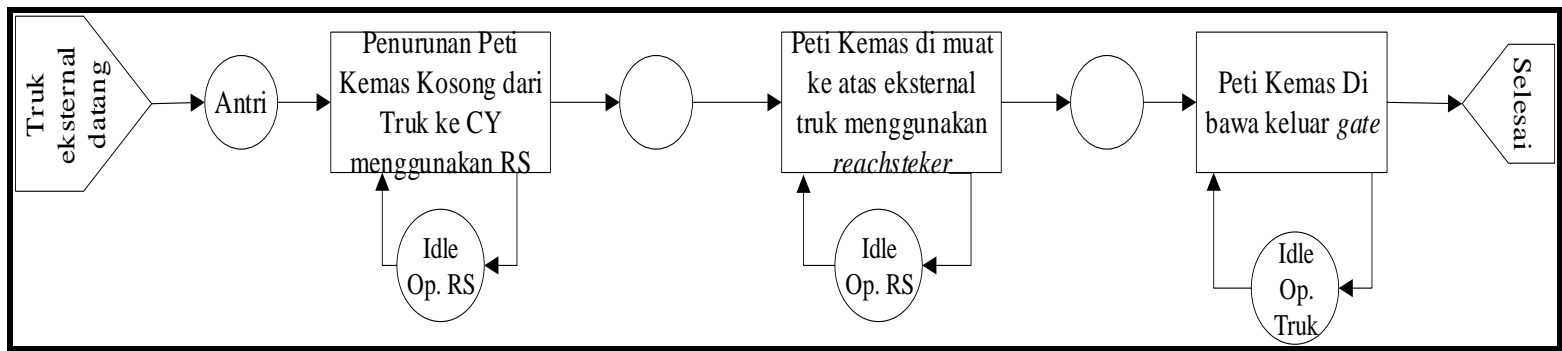

Gambar 4 ACD model 2

b. Uji Keseragaman dan Kecukupan Data

Pengujian dilakukan terhadap 30 aktifitas yang terjadi pada 7 proses (satuan yang digunakan adalah detik):

Uji Keseragaman data dengan tingkat kepercayaan $95 \%$ :

$$
\begin{gathered}
\bar{t}=\frac{\sum t}{n}=\frac{2308}{30}=98,33 \\
\sigma_{\bar{t}}=6,51 \\
B K A=\bar{t}+k \sigma_{\bar{t}}=98,33+2(6,51) \\
=111 \\
B K B=\bar{t}-k \sigma_{\bar{t}}=98,33-2(6,51) \\
=85
\end{gathered}
$$

BKB : Batas kontrol bawah untuk menentukan nilai terendah dari data yang digunakan dalam uji keseragaman.

Uji kecukupan data $(\mathrm{N}=30)$ :

$$
\begin{gathered}
N^{1}=\left(\frac{\frac{2}{0,05} \sqrt{30 \times(291.312)-(8.702 .500)}}{2950}\right)^{2} \\
N^{1}=6,77 \approx 7
\end{gathered}
$$

BKA : Batas kontrol atas untuk menentukan batas atas dari data yang digunakan dalam uji keseragaman

$\mathrm{N}>\mathrm{N}^{\prime} \quad$ (Data cukup) 
Tabel 1. Hasil rekapitulasi keseragaman dan kecukupan data

\begin{tabular}{|c|c|c|c|c|c|c|c|c|}
\hline \multirow{2}{*}{ No. } & \multirow{2}{*}{ Proses } & \multicolumn{4}{|c|}{ Uji Keseragaman Data } & \multicolumn{3}{|c|}{ Uji Kecukupan Data } \\
\hline & & Min & $\mathrm{BKB}$ & Max & BKA & $\mathrm{N}$ & $\mathrm{N}^{1}$ & Hasil \\
\hline 1 & Bongkar CT dari kapal ke dermaga & 88 & 85 & 110 & 111 & 30 & 7 & $\begin{array}{l}\text { Seragam dan } \\
\text { cukup }\end{array}$ \\
\hline 2 & Transport dari dermaga ke CY & 260 & 253 & 347 & 358 & 30 & 1 & $\begin{array}{l}\text { Seragam dan } \\
\text { cukup }\end{array}$ \\
\hline 3 & Penurunan container & 62 & 59 & 80 & 81 & 30 & 1 & $\begin{array}{l}\text { Seragam dan } \\
\text { cukup }\end{array}$ \\
\hline 4 & Gate In Truk Eksternal & 66 & 58 & 96 & 96 & 30 & 24 & $\begin{array}{l}\text { Seragam dan } \\
\text { cukup }\end{array}$ \\
\hline 5 & Penurunan CT Kosong & 90 & 90 & 110 & 114 & 30 & 6 & $\begin{array}{l}\text { Seragam dan } \\
\text { cukup }\end{array}$ \\
\hline 6 & Pemuatan CT ke Truk & 95 & 95 & 104 & 107 & 30 & 2 & $\begin{array}{l}\text { Seragam dan } \\
\text { cukup }\end{array}$ \\
\hline 7 & Gate Out Truk Eksternal & 25 & 24 & 35 & 36 & 30 & 15 & $\begin{array}{l}\text { Seragam dan } \\
\text { cukup }\end{array}$ \\
\hline
\end{tabular}

Dari Tabel 1 hasil ujian keseragaman dam kecukupan data menunjukkan bahwa data yang diambil telah seragam dan cukup, hal ini ditunjukkan Uji keseragaman data dengan min $\geq B K B$ dan max $\leq$ BKA sedangkan untuk

\section{c. Perancangan Model ExtendSim}

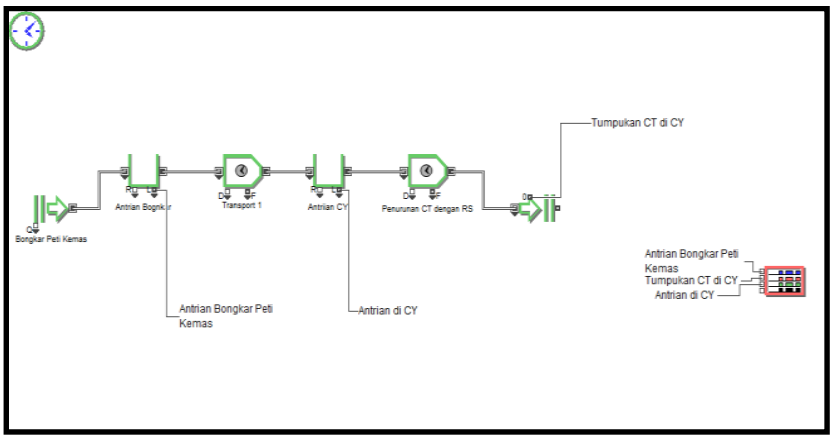

Gambar 5 Model extendSim model 1

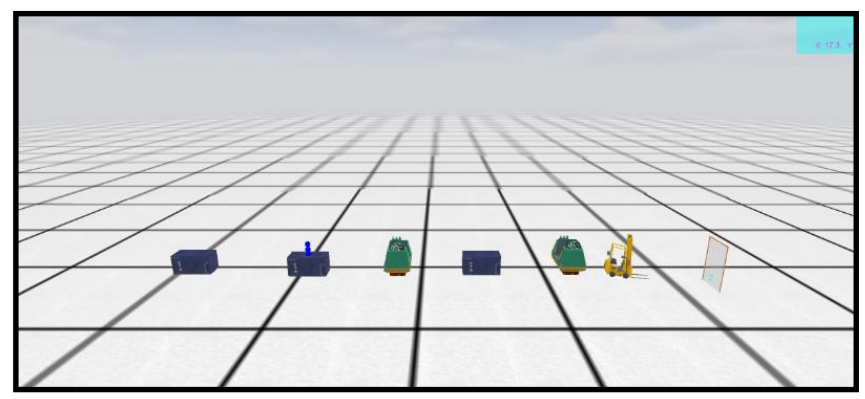

Gambar 6 Model 3D model 1 kecukupan data $\mathrm{N}>\mathrm{N}^{1}$. Karena data waktu telah seragam dan cukup untuk dijadikan input simulasi. 


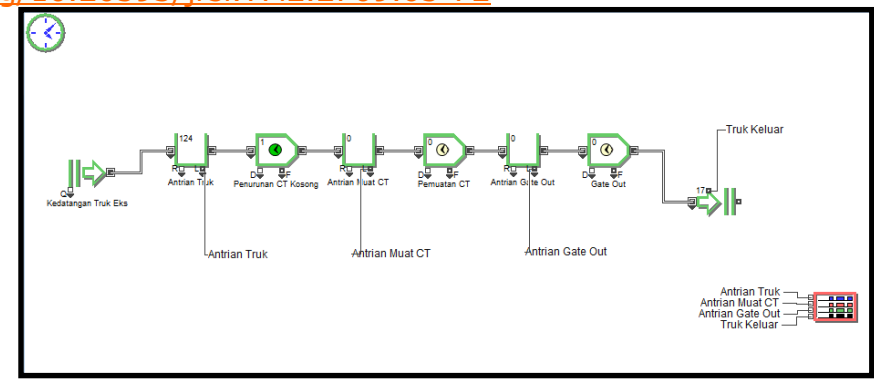

Gambar 7 Model extendSim model 1

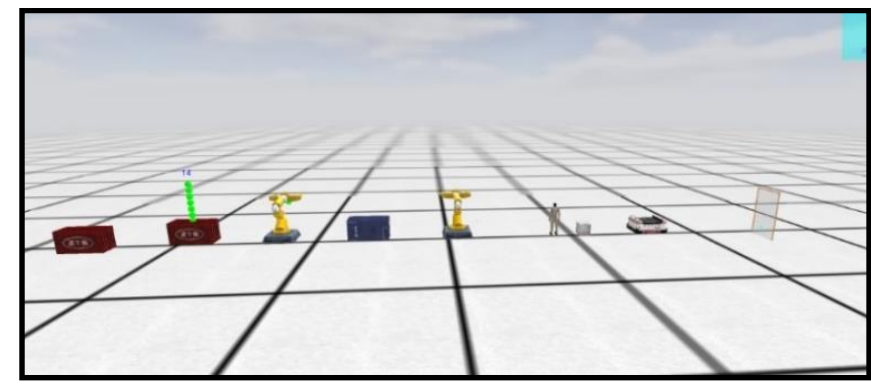

Gambar 8 Model 3D model 2

\section{d. Penentuan Jumlah Replikasi}

Penentuan jumlah replikasi perlu dilakukan untuk menentukan berapa kali pengulangan simulasi yang perlu dilakukan untuk mendapatkan hasil yang valid. Untuk menentukan berapa jumlah replikasi yang dibutuhkan maka berdasarkan Law \& Kelton (1991) dilakukan running model awal sebanyak 10 kali replikasi, lalu dilakukan perhitungan penentuan jumlah replikasi dengan menggunakan metode absolute error.

Dengan interval kepercayaan sebesar 95\% maka perhitunganya adalah:

$$
\begin{aligned}
\mathrm{n} & =10 \\
\mathrm{n}-1 & =9 \\
\alpha & =0.05 \\
\text { hw } & =\frac{\left(\mathrm{t}_{\mathrm{n}}-1 \cdot \frac{\alpha}{2}\right) \times \mathrm{S}}{\sqrt{\mathrm{n}}}
\end{aligned}
$$

$$
\begin{aligned}
& =\frac{2.262 \times 0.567}{\sqrt{10}} \\
& =\frac{1.28}{3.16}=0.406 \\
\mathrm{n}, \quad & =\left[\frac{\left(\mathrm{z} \frac{\alpha}{2}\right) \mathrm{s}}{\mathrm{hw}}\right]^{2} \\
& =\left[\frac{1,96 \times 0,567}{0,406}\right]^{2} \\
& =7.508 \approx 8
\end{aligned}
$$

Dari perhitungan yang telah dilakukan diperoleh jumlah replikasi yang dibutuhkan sebanyak 8 kali.

\section{e. Simulasi Kondisi Awal}

Hasil simulasi kondisi awal, simulasi dilakukan sebanyak 8 kali replikasi, berdasarkan perhitungan kebutuhan replikasi optimal:

Tabel 2. Hasil simulasi kondisi awal

\begin{tabular}{|c|c|c|c|c|}
\hline \multirow{2}{*}{ Replikasi Ke- } & \multicolumn{2}{|c|}{ Model 1 } & \multicolumn{2}{c|}{ Model 2 } \\
\cline { 2 - 5 } & Antrian & $\begin{array}{c}\text { Jumlah } \\
\text { Output }\end{array}$ & Antrian & $\begin{array}{c}\text { Jumlah } \\
\text { Output }\end{array}$ \\
\hline 1 & 130 & 47 & 126 & 17 \\
\hline 2 & 130 & 46 & 125 & 17 \\
\hline 3 & 129 & 48 & 125 & 18 \\
\hline 4 & 132 & 47 & 125 & 17 \\
\hline 5 & 130 & 47 & 124 & 17 \\
\hline 6 & 131 & 47 & 126 & 18 \\
\hline 7 & 128 & 48 & 124 & 17 \\
\hline 8 & 128 & 47 & 125 & 17 \\
\hline Total & $\mathbf{1 0 3 8}$ & $\mathbf{3 7 7}$ & $\mathbf{1 0 0 0}$ & $\mathbf{1 3 8}$ \\
\hline Rata-rata & $\mathbf{1 2 9 . 7 5}$ & $\mathbf{4 7 . 1 2 5}$ & $\mathbf{1 2 5}$ & $\mathbf{1 7 . 2 5}$ \\
\hline
\end{tabular}


Dari tabel hasil simulasi yang dilakukan selama 2 jam terlihat bahwa jumlah antrian yang terdapat baik di model 1 maupun model 2 sangat tinggi, tidak seimbang dengan jumlah output yang ada. Hal ini menandakan perlunya perbaikan (skenario perbaikan) untuk meningkatkan pelayanan yang ada di dermaga peti kemas PT. X.

\section{f. Skenario Perbaikan}

Perancangan skenario perbaikan dilakukan untuk mendapatkan hasil simulasi yang lebih baik dari simulasi kondisi aktual, artinya akan ada penambahan penambahanpenambahan alat sebagai skenario perbaikan pada dermaga peti kemas PT. X.

Tabel 3. Pemilihan skenario

\begin{tabular}{|c|c|c|c|c|c|}
\hline \multirow[b]{2}{*}{ No } & \multirow[b]{2}{*}{$\begin{array}{c}\text { Nama } \\
\text { Skenario }\end{array}$} & \multicolumn{2}{|c|}{ Model 1} & \multicolumn{2}{|c|}{ Model 2} \\
\hline & & Output & $\begin{array}{c}\text { Utilitas } \\
(\%)\end{array}$ & Output & Utilitas(\%) \\
\hline 1 & Model Awal & 47 & 1 & 17 & 1 \\
\hline 2 & Alternatif 1 & 99 & 0,997 & 34 & 0,996 \\
\hline 3 & Alternatif 2 & 140 & 0,994 & 56 & 0,992 \\
\hline
\end{tabular}

Dari tabel 3 diatas terlihat bahwa penambahan truk transport pada model 1 sebanyak 2 buah untuk alternatif ke 2 memiliki output yang sangat jauh dibandingkan dengan kondisi eksisting. Pada model 2 penambahan reachsteker mempengaruhi jumlah peti kemas yang dapat diselesaikan terutama pada alternatif ke dua.

\section{g. Perhitunan YOR dan BOR}

Perhitungan nilai YOR dan BOR digunakan untuk mengetahui apakah nilai YOR dan BOR di dermaga peti kemas pelabuhan $\mathrm{X}$ sudah sesuai standar apa belum dan sebagai acuan dalam perbaikan prosedur yang akan dilakukan.

Perhitungan Nilai YOR (Yard Occupancy Ratio)

Perhitungan nilai YOR dilakukan untuk mengetahui apakah kapasitas lapangan penumpukan (CY) masih dapat memenuhi jumlah peti kemas sesuai hasil peramalan (Supriyono, 2013), kondisi awal sendiri kapasitas CY adalah 2.046 TEU dengan 5 blok, dan pada rekomendasi perbaikan akan ditambahkan menjadi 3.800 TEU untuk memenuhi penambahan kapasitas peti kemas berdasarkan hasil peramalan.
Perhitungan YOR dengan Kapasitas Awal (2046 TEU)

$$
\begin{gathered}
Y O R=\frac{\text { Capacity Used }}{\text { Capacity Available }} \times 100 \% \\
\rightarrow \frac{(1.400)}{(2.046)} \times 100 \% \\
=68,41 \%
\end{gathered}
$$

Perhitungan BOR dengan Kapasitas Tambahan (3800 TEU)

$$
\begin{gathered}
Y O R=\frac{\text { Capacity Used }}{\text { Capacity Available }} \times 100 \% \\
\rightarrow \frac{(1.400)}{(3.800)} \times 100 \% \\
=36,83 \%
\end{gathered}
$$

Perhitungan Nilai BOR (Berth Occupancy Ratio)

$B O R$

$$
\begin{aligned}
& =\frac{\text { Vs } \times \text { St } \times(\text { Panjang Kapal }+5)}{\text { WE } \times \text { Panjang Dermaga }} \times 100 \% \\
& \rightarrow \frac{13 \times 21 \times(120+5)}{(24 \times 30) \times 400} \times 100 \%=11,57 \%
\end{aligned}
$$


Tabel 4. Rekapitulasi hasil perhitungan YOR dan BOR

\begin{tabular}{|l|l|l|l|l|l|}
\hline Bulan & $\begin{array}{l}\text { Arus Peti } \\
\text { Kemas } \\
(\text { TEU) }\end{array}$ & $\begin{array}{l}\text { Kedatangan } \\
\text { Kapal }\end{array}$ & YOR Awal & $\begin{array}{l}\text { YOR } \\
\text { Perbaikan }\end{array}$ & BOR \\
\hline Jan 2019 & 1399,7 & 12,7 & 68,4 & 36,8 & 11,6 \\
\hline Feb 2019 & 1463,2 & 13,3 & 71,5 & 38,5 & 12,1 \\
\hline Mar 2019 & 1526,7 & 13,9 & 74,6 & 40,2 & 12,7 \\
\hline Apr 2019 & 1590,2 & 14,5 & 77,7 & 41,8 & 13,2 \\
\hline Mei 2019 & 1653,7 & 15,1 & 80,8 & 43,5 & 13,7 \\
\hline Jun 2019 & 1717,2 & 15,7 & 83,9 & 45,2 & 14,3 \\
\hline Jul 2019 & 1780,7 & 16,3 & 87,0 & 46,9 & 14,8 \\
\hline Agust 2019 & 1844,2 & 16,9 & 90,1 & 48,5 & 15,4 \\
\hline Sept 2019 & 1907,7 & 17,5 & 93,2 & 50,2 & 15,9 \\
\hline Okt 2019 & 1971,2 & 18,0 & 96,3 & 51,9 & 16,4 \\
\hline Nov 2019 & 2034,7 & 18,6 & 99,4 & 53,5 & 17,0 \\
\hline Des 2019 & 2098,2 & 19,2 & 102,5 & 55,2 & 17,5 \\
\hline Jan 2020 & 2161,7 & 19,8 & 105,7 & 56,9 & 18,1 \\
\hline Feb 2020 & 2225,2 & 20,4 & 108,8 & 58,6 & 18,6 \\
\hline Mar 2020 & 2288,7 & 21,0 & 111,9 & 60,2 & 19,2 \\
\hline Apr 2020 & 2352,2 & 21,6 & 115,0 & 61,9 & 19,7 \\
\hline Mei 2020 & 2415,7 & 22,2 & 118,1 & 63,6 & 20,2 \\
\hline Jun 2020 & 2479,2 & 22,8 & 121,2 & 65,2 & 20,8 \\
\hline Jul 2020 & 2542,7 & 23,4 & 124,3 & 66,9 & 21,3 \\
\hline Agust 2020 & 2606,2 & 24,0 & 127,4 & 68,6 & 21,9 \\
\hline Sept 2020 & 2669,7 & 24,6 & 130,5 & 70,3 & 22,4 \\
\hline Okt 2020 & 2733,2 & 25,2 & 133,6 & 71,9 & 22,9 \\
\hline Nov 2020 & 2796,7 & 25,8 & 136,7 & 73,6 & 23,5 \\
\hline Des 2020 & 2860,2 & 26,4 & 139,8 & 75,3 & 24,0 \\
\hline & & & & & \\
\hline
\end{tabular}

\section{Kesimpulan}

a. Hasil simulasi untuk sistem bongkar muat peti kemas Dermaga $X$ menunjukkan jumlah output sebanyak 47 ada model 1 dan 17 pada model 2, maka dilakukan 4 rancangan skenario perbaikan 2 untuk model 1 dan 2 untuk model 2. Skenario terpilih adalah skenario 2 untuk model 1 dan 2 dengan output secara beruturut turut adalah 140 dan 56.

b. Perhitungan nilai YOR yaitu sebesar $68,4 \%$, nilai BOR sebesar $11,6 \%$ dan utilitas tertinggi mencapai $100 \%$ untuk transport dan reachsteker. Perbaikan kapasitas perlu dilakukan pada bulan November 2019 karena sudah memenuhi angka 100\%, maka dilakukan perbaikan berupa penambahan kapasitas container yard dari 2.046 TEU menjadi 3.800 TEU, hingga bulan Desember 2020 kapasitas CY masih tetap optimal yaitu sebesar 75,3 \%. Sedangkan untuk nilai BOR masih tetap optimal hingga tahun 2020 dengan kapasitas tertinggi sebesar $24,0 \%$ sehingga tidak diperlukan penambahan Panjang dermaga.

\section{Daftar Pustaka}

Banks, J., Carson, J. S., Nelson, B. L. dan Nicol, D. M. Discrete-Event System Simulation Fourth Edition. New Jersey: Pearson, 2005.

Danu, F., dan Tirto. "Optimasi Kapasitas Dermaga Internasional Dengan Simulasi Pada PT Terminal Teluk Lamong." Tesis. 2017.

ExtendSim. ExtendSim Users Guide. San Jose, USA. Imagine That Inc. 2017.

Fadillah, R.A., "Pengaturan Dwelling Time PT. Pelindo II di Pelabuhan Panjang." Skripsi. Fakultas Hukum Universitas Lampung Bandar Lampung. 2018.

Kang, D., dan Choi, B.K., "Visual Modeling And Simulation Toolkit For Activity Cycle Diagram", Proceedings 24th European Conference on Modelling and Simulation 
ECMS. ISBN: 978-0-9564944-0-5 / ISBN: 978-0-9564944. 2010.

Law, A.M. dan Kelton, W.D., Simulation Modelling and Analysis. McGraw-Hill: Singapore. 2000.

Rohmandani, R. "Perancangan Model Simulasi Untuk Mengoptimalkan Waktu Pelayanan Pada Pelabuhan Merak. Teknik Industri." Fakultas Teknik. Universitas Indonesia. 2009.

Siswadi, dan Mujiarto, I.. "Optimasi Sistem Pelayanan Bongkar Muat Peti Kemas di Pelabuhan Tanjung Emas Semarang Dengan Model Simulasi Antrian." Prosiding SNST Ke-4. 2013. ISBN: 978602-99334-2-0

Supriyono. "Analisis Kinerja Terminal Petikemas di Tanjung Perak Surabaya: (Study Kasus: PT. Terminal Petikemas Surabaya)."Jurnal MKTS, 2013.

Sutini. "Analisis Biaya Bongkar Muat Saat Kapal Memasuki Alur Masuk Pelabuhan Tanjung Emas Semarang". Jurnal Saintek Maritim 17, No. 1. 2017.

Triatmodjo, B. Perencanaan Pelabuhan. Yogyakarta: Beta Offset Yogyakarta. 2010. 